\section{Occurrence of intestinal parasites amongst persons on highly active antiretroviral drug therapy in Calabar, Cross River State, Nigeria}

\author{
Paul C. Inyang-Etoh, \\ Mfoniso I. Udonkang, \\ Adepelumi O. Adeboboye \\ Department of Medical Laboratory \\ Science, Faculty of Allied Medical \\ Sciences, College of Medical Sciences, \\ University of Calabar, Nigeria
}

\section{Abstract}

Opportunistic and intestinal parasite infections are common health problem among HIV/AIDS patients. Early detection and treatment of these parasites are important to improve the quality of life of this category of patients. The occurrence of intestinal parasites among 400 patients on highly active antiretroviral drug therapy (HAART) aged 11-60 years was investigated. Standard parasitological techniques like direct microscopy, formol ether concentration and modified ZiehlNeelsen staining techniques were used to analyze the stool samples. Intestinal parasite infections were positive in 116 (29\%) of the subjects on HAART while control subjects had $12(12 \%)$ and the difference was statistically significant $(\mathrm{P}<0.05)$. Subjects in the age group 21-30 years had the highest infection rate 54 (35.1\%). There was no statistically significant difference in infection according to age ( $P>0.05)$. Females 76 (32.5\%) had a higher prevalence rate than males 40 (24.1\%). But there was no statistically significant difference in infection according to gender $(\mathrm{P}>0.05)$. Patients with CD4 count of less than 200 cells $/ \mathrm{mm}^{3}$ were observed to be more infected than those with CD4 count of more than 200 cells $/ \mathrm{mm}^{3}$. There was a strong positive correlation $(r=0.94)$ between CD4 count and the occurrence of intestinal parasite infection. Protozoan parasites 84 (21.0\%) accounted for a higher prevalence rate than helminthic parasites 32 (8.0\%). These findings has revealed a high prevalence of intestinal parasite infection among patients on HAART thus the routine screening of stool samples from these category of patients for intestinal parasites is advocated for effective management of the disease.

\section{Introduction}

Intestinal parasitic infections are common in Sub-Saharan Africa where the majority of Human Immune Deficiency Virus (HIV)Acquired Immunodeficiency Syndrome (AIDS) cases are concentrated. ${ }^{1}$ One of the major health problems in patients with HIV is superimposed infections due to reduced immunity. The lack of knowledge coupled with these intestinal parasites not being included in routine diagnostic testing have unknowingly contributed to these parasites being perceived as uncommon. ${ }^{2}$ In the last few years, advances in HAART have led to improvements in immunological state with a resulting reduction in the frequency of certain intestinal parasites. -5 $^{-5}$ Unsanitary conditions, poverty and malnutrition promote transmission of intestinal parasite infections.6,7 Some of these parasites may disseminate to other organs such as the bronchioles, bile ducts and liver, producing symptoms specific to the organs affected. ${ }^{8}$ Patients with CD4 counts $>200$ cells $/ \mathrm{mm}^{3}$ usually have self-limiting infections, whereas most patients with counts $<140$ cells $/ \mathrm{mm}^{3}$ develop severe and persistent infections. ${ }^{9}$ Intestinal parasitic infections that are asymptomatic or cause self-limiting diarrhea in immunocompetent individuals can cause profuse diarrhea in immunocompromized individuals, generally accompanied by weight loss, anorexia, malabsorption, and in some cases fever and abdominal pain. ${ }^{10}$ This study is however designed to establish the prevalence and pattern of parasitic infections, and also correlate CD4 levels with its prevalence among persons on Highly Active Antiretroviral Drug Therapy in Calabar Metropolis, Nigeria.

\section{Materials and Methods}

\section{Study area}

This study was conducted in Calabar, the state capital of Cross River State. Basically, Calabar Metropolis is made up of two local government areas (LGAs), Calabar Municipality and Calabar South LGA in Cross River State which is within the rainforest belt of Nigeria. According to 2006 National Population Census, the total population of Calabar was estimated at $371,022.11$ Geographically, Calabar is located on $4^{\circ} 58^{\prime} 34^{\prime \prime} \mathrm{N}$ and $8^{\circ} 20^{\prime} 50^{\prime \prime}$ E. The city is bounded westward by the Calabar River, to the North is bound by Odukpani Local Government Area, the near East stretches the Great Qua River and Akpabuyo Local Government Area and to the far South are swamps, creeks and the Atlantic ocean. Calabar Metropolis is a cosmopolitan city virtually embracing all ethnic groups in Nigeria and therefore presents a good case study. 12
Correspondence: Paul C. Inyang-Etoh, Medical Laboratory Science Department, Faculty of Allied Medical Sciences, College of Medical Sciences, University of Calabar, P. M. B. 1278, Calabar, Cross River State, Nigeria.

Tel.: +234.803.723.7567.

E-mail: inyangetoh@yahoo.com

Key words: Calabar, antiretroviral drug therapy, protozoa, helminthes.

Acknowledgements: the authors acknowledge and appreciate the management and staff of Incopa Medical Laboratories, Calabar for approving the use of some of their equipments during the research work. We are grateful to the management and staff of Heart to Heart Centre in the two hospitals in Calabar for their assistance and also giving us access to their patients. We are also grateful to Miss Mfonobong Simeon for the technical assistance rendered during the analysis of samples and Miss Margaret Edem for typing this document.

Contributions: PCI, conception and design of the research work, arrangement and presentation of manuscript, data analysis and interpretation, final approval of manuscript; MIU, collection and examination of stool sample (direct smear and concentration method), modified technique for stool examination; AOA, collection and examination of stool sample (direct smear and concentration method), collection of blood for HIV screening and CD4 count.

Conflict of interest: the authors declare no potential conflict of interest.

Received for publication: 7 January 2015. Revision received: 7 February 2015.

Accepted for publication: 10 February 2015.

This work is licensed under a Creative Commons Attribution NonCommercial 3.0 License (CC BYNC 3.0).

(C) Copyright P.C. Inyang-Etoh et al., 2015 Licensee PAGEPress srl, Italy

Veterinary Science Development 2015; 5:5794 doi:10.4081/vsd.2015.5794

\section{Highly active antiretroviral drug} therapy

Highly active antiretroviral drug therapy (HAART) is the name given to aggressive treatment regimens used to suppress HIV viral replication and the progression of HIV disease. The usual HAART regimen combines three or more different drugs such as two nucleoside reverse transcriptase inhibitors (NRTIs) and a protease inhibitor (PI), two NRTIs and a nonnucleoside reverse transcriptase inhibitor (NNRTI) or other such combinations. These HAART regimens have proven to reduce the amount of active virus and in some cases can 
lower the number of active virus until it is undetectable by current blood testing techniques.

\section{Study population}

The study population were unselected 400 subjects (116 males and 134 females) aged 1160 years attending the HIV Clinic at the University of Calabar Teaching Hospital (UCTH) and the State General Hospital which are both located in Calabar Metropolis. Moreover 100 HIV negative (healthy) subjects (40 male and 60 female) were used as controls.

\section{Ethical approval and informed con- sent}

Subjects for the study were enrolled after due approval from the Ethical Research Committee of the Cross River State Ministry of Health. Patients or Guardians were made to sign a consent form before enrollment.

\section{Collection of samples}

A total of 400 samples were collected into clean, leak-proof, wide-mouthed universal container issued to each of the patients. The samples were then transported to the parasitology laboratory in University of Calabar Teaching Hospital (UCTH) as soon as possible for parasitological analysis. Samples that were not analyzed immediately were preserved in $10 \%$ formol-saline. Blood samples were also collected from same number of patients for confirmation of HIV status and CD4 count.

\section{Laboratory diagnosis}

\section{Macroscopic examination}

Samples were examined macroscopically in the laboratory noting their color, consistency and the presence of blood, mucus, adult worm or segmented worms.

\section{Direct microscopic examination}

A peanut size of the stool sample was collected from the sample container and homogenized with a few drops of normal saline. An aliquot of the homogenate was used in making the direct smear. On a separate slide, a drop of the homogenized sample was placed at the center of the two slides. A drop of saline was added to the first slide, and also a drop of iodine to the other slide. A coverslip was then placed over each sample on the side. The preparation was then examined microscopically using $10 \times$ objective, and a confirmation of any identified parasite was done with the $40 x$ objective.

\section{Formol-ether concentration tech- nique}

This was performed according to the meth- ods. ${ }^{13}$ Half a teaspoonful of stool was thoroughly mixed in $10 \mathrm{~mL}$ of water and strained via two layers of gauze in a funnel; the filtrate was centrifuged at $2000 \mathrm{rpm}$ for 2 minutes. The supernatant was discarded and the sediment resuspended in $10 \mathrm{~mL}$ of normal saline. It was again centrifuged and the supernatant discarded. The sediment was then resuspended in $7 \mathrm{~mL}$ formol saline and allowed to stand for 10 minutes for fixation. To this, $3 \mathrm{~mL}$ of ether was added. The tube was stoppered and shaken vigorously to mix. The stopper was then removed and the tube centrifuged at $2000 \mathrm{rpm}$ for 2 minutes. The tube was allowed to stand for two minutes. Four layers became visible, the top layer comprised ether, second was a plug of debris, and the third was a clear layer of formal saline, while the fourth had the sediment. The plug of debris was detached from the side with the aid of a glass rod and the liquid poured off leaving a small amount of formal saline for resuspension of the sediment. The sediment was then poured on a clean glass slide, covered with a coverslip and examined microscopically.

\section{Identification of parasite species}

The microscopic examination of direct smear and stool deposits after an iodine stained, formol-ether concentration method revealed the characteristic ova of nematodes. Ancylostoma duodenale was differentiated from Necator americanus by its buccal cavity which bears two hook like teeth on the top and two triangular cutting plates on the bottom while the mouth of $N$. americanus has four cutting plates, two on the ventral and two on the dorsal surfaces.

\section{Special technique}

This consists of the modified Ziehl-Neelsen staining technique. It is modified, because this technique does not require heating as compared to the conventional Ziehl-Neelsen staining procedure. It is used specifically for the identification of coccidian parasites such as Cryptosporidium parvum, Isospora belli and Cyclospora species in stool samples.

\section{Procedure}

We proceeded as follows: i) a smear was prepared from the sediment obtained by the formal ether concentration technique. It was airdried and fixed with methanol for 2 minutes. ii) It was then stained with unheated carbol fuchsin for 15 minutes, and washed off the stain with water. iii) The smear was decolorized with $1 \%$ acid alcohol for 10 seconds, and washed off with water. iv) It was then counterstained with $0.5 \%$ malachite green for $30 \mathrm{sec}$ onds, washed off with water and the slide was allowed to stand in a draining rack for the smear to dry. v) It was examined microscopically using a lower power magnification to detect oocysts and the oil immersion objective to identify them.

\section{HIV screening test}

HIV screening was done using the serial algorithm of screening with determine and confirmed result with Unigold.

Alere determine HIV1/2 is an immunechronmatographically test for the qualitative detection of antibodies to HIV-1 and HIV-2.

\section{HIV confirmatory test using unigold}

All the test samples that were positive with determine were confirmed with a second test using Uni-Gold. For testing, two drops of whole blood from the pricked finger were allowed to fall into the sample port, followed by two drops of wash buffer and allowed to react. Antibodies of HIV-1 or HIV-2 proteins were bound to the colloidal gold linked antigens. The antibody protein colloidal gold complex moves chromatographically along the membrane to the test and control regions of the test device. A positive reaction is visualized by a pink band in the test region of the device and in the control line. A negative reaction occurs in the absence of human immunoglobin antibodies to HIV in the analyzed specimen. Consequently no visually detectable band develops in the test region of the device.

\section{Analysis of whole blood for CD4 cell count}

$\mathrm{CD}_{4}$ count was analyzed using Partec CyFlow counter made in Germany. Briefly, $20 \mathrm{~mL}$ fresh whole EDTA blood was added to $20 \mathrm{~mL}$ $\mathrm{CD}_{4} / \mathrm{MAb}$ in a test tube and incubated in the dark at room temperature for 15 minutes, and $800 \mathrm{~mL}$ of buffer was added, connected to the CyFlow and allowed to run. Automatically generated report of the blood sample becomes displayed on the screen of the machine.

\section{Data analysis}

Difference in proportion was evaluated using the Chi-square test. Pearson's correlation co-efficient was used to determine the correlation of the variables. Statistical significance difference was achieved if $\mathrm{P}<0.05$.

\section{Results}

The results of the study on the intestinal parasite load among 400 patients on HAART aged 11-60 years is presented below. Table 1 shows the prevalence of intestinal parasites among patients on antiretroviral drug therapy according to age. Out of a total of 400 HIV seropositive individuals on antiretroviral drug therapy who participated in the study, 116 (29\%) were positive for intestinal parasite. 
Subjects aged 21-30 had the highest prevalence rate $(35.1 \%)$ while those aged $11-20$ years had the lowest prevalence rate of (18.2\%). There was no statistically significant difference in infection according to age $\left(\chi^{2}\right.$ $=7.51 \mathrm{df}(4) \mathrm{P}>0.05)$. The distribution of intestinal parasites among patients on antiretroviral drug therapy according to their CD4 cell counts is shown on Table 2. Protozoan parasites 84 (21.0\%) accounted for a higher prevalence rate than helminthic parasite infections $32(8.0 \%)$.

Figure 1 shows the gender effect on the prevalence of intestinal parasites in patients on antiretroviral drug therapy. Females 76 (32.5\%) had a higher prevalence rate than males 40 (24.1\%). But there was no statistically significant difference in infection according to gender $\left(\chi^{2}=5.2 \mathrm{df}(1) \mathrm{P}>0.05\right)$.

Figure 2 shows the distribution of intestinal parasites among patients on antiretroviral drug therapy according to species. Patients with CD4 count of less than 200 cells $/ \mathrm{mm}^{3}$ were observed to be more infected than those with CD4 count of more than 200 cells $/ \mathrm{mm}^{3}$. There was a strong positive correlation $(r=0.94)$ between CD4 count and the occurrence of intestinal parasite infection.

\section{Discussion and Conclusions}

Intestinal parasite infection has been one of the major contributing factors to the morbidity and mortality of HIV/AIDS patients in most developing countries where HIV/AIDS cases are common. With the advent of HAART, HIV-associated morbidity and mortality has dramatically decreased in many high-income countries. This study was an attempt to establish the enormity of the prevalence of intestinal parasites among patients on HAART Calabar, Cross River state.

The $29 \%$ prevalence rate in intestinal parasite infection observed in this study is higher than 8.7\% earlier reported by Etok et al., ${ }^{14}$ at the General Hospital, Calabar and $17.6 \%$ reported by Missaye et al., 15 in South Wollo zone of Amhara region state, North-East Ethiopia. The reason for the high prevalence rate (29\%) of intestinal parasites infection in the study area may be due to the increase in influx of tourist and also the corresponding increase in the number of this category of patients from the rural areas and the associated poor nutrition and sanitary conditions of the people from rural settings. However, this value is

Table 1. the prevalence of intestinal parasites among patients on antiretroviral drug therapy according to age group.

\begin{tabular}{lcccc}
$\begin{array}{l}\text { Age range } \\
\text { (years) }\end{array}$ & $\begin{array}{c}\text { Test subjects } \\
\text { Positive for }\end{array}$ & $\begin{array}{c}\text { Control sulbjects } \\
\text { Examined } \\
\text { parasites (\%) }\end{array}$ & $\begin{array}{c}\text { Positive for } \\
\text { parasites (\%) }\end{array}$ \\
\hline $11-20$ & 22 & $4(18.2)$ & 5 & $1(20)$ \\
$21-30$ & 154 & $54(35.1)$ & 38 & $5(13.2)$ \\
\hline $31-40$ & 146 & $36(24.7)$ & 36 & $4(11.1)$ \\
$41-50$ & 64 & $18(28.1)$ & 18 & $2(11.1)$ \\
\hline $51-60$ & 14 & $4(28.6)$ & 3 & $0(0.0)$ \\
Total & 400 & $116(29)$ & 100 & $12(12.0)$
\end{tabular}

Table 2. Distribution of intestinal parasites among patients on antiretroviral drug therapy according to their $\mathrm{CD} 4$ cell counts $(\mathrm{N}=400)$

\begin{tabular}{|c|c|c|c|}
\hline Parasites & $<200(n=122)$ & $\begin{array}{c}\text { CD4 count (cells } / \mathrm{mm}^{3} \\
201-400(\mathrm{n}=196)\end{array}$ & $>400(n=82)$ \\
\hline $\begin{array}{l}\text { Protozoa } \\
\text { Giardia intestinalis } \\
\text { Entamoeba histolytica/dispar } \\
\text { Cryptosporodium sp } \\
\text { Isospora belli } \\
\text { Total }\end{array}$ & $\begin{array}{c}4(3.3 \%) \\
10(8.2 \%) \\
32(26.2 \%) \\
2(1.6 \%) \\
48(39.3 \%)\end{array}$ & $\begin{array}{c}0(0 \%) \\
24(12.2 \%) \\
6(3.1 \%) \\
0(0 \%) \\
30(15.3 \%)\end{array}$ & $\begin{array}{c}0(0 \%) \\
6(7.3 \%) \\
0(0 \%) \\
0(0 \%) \\
6(7.3)\end{array}$ \\
\hline $\begin{array}{l}\text { Helminthes } \\
\text { Trichuris trichiura } \\
\text { Ascaris lumbricoides } \\
\text { Ancylostoma duodenale } \\
\text { Strongyloides sp } \\
\text { Total } \\
\text { Grand total }\end{array}$ & $\begin{array}{l}6(4.9 \%) \\
2(1.6 \%) \\
2(1.6 \%) \\
2(1.6 \%) \\
12(19.5 \%) \\
60(49.0 \%)\end{array}$ & $\begin{array}{c}0(0 \%) \\
14(7.1 \%) \\
6(3.1 \%) \\
0(0 \%) \\
20(10.2 \%) \\
50(25.5 \%)\end{array}$ & $\begin{array}{l}0(0 \%) \\
0(0 \%) \\
0(0 \%) \\
0(0 \%) \\
0(0 \%) \\
6(7.3 \%)\end{array}$ \\
\hline
\end{tabular}

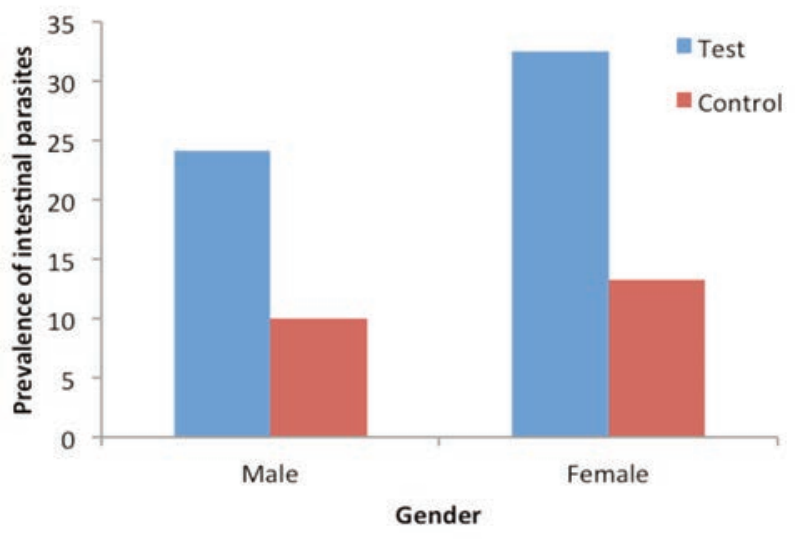

Figure 1. The gender effect of prevalence of intestinal parasites in patients on antiretroviral drug.

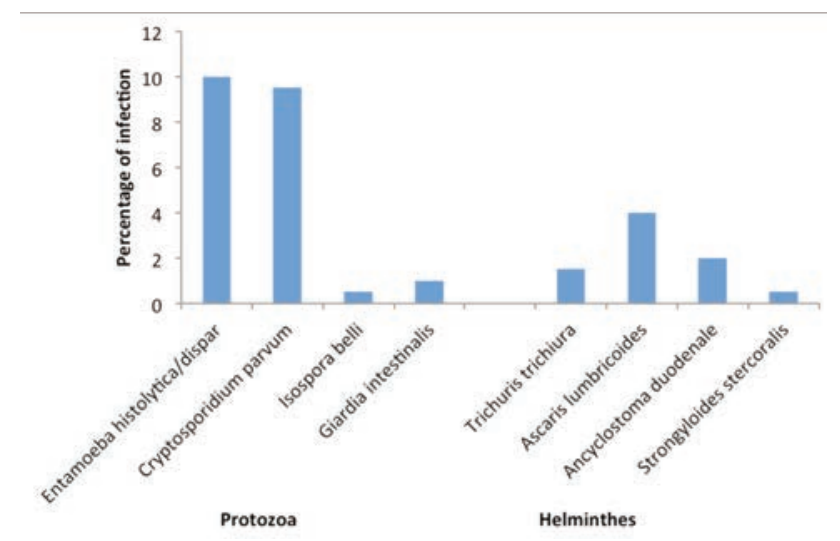

Figure 2. Distribution of intestinal parasites among patients on antiretroviral drug. 
lower than the $59.5 \%$ reported by Nkenfou et al., ${ }^{16}$ in Dischang, Cameroon and $48 \%$ reported by Adamu and Petros, in Adama, Afar and Dire-Dana in Ethiopia. ${ }^{17}$ In other parts of Nigeria, results on similar studies have been reported. Abaver et al., 18 reported 24.7\% in Abuja, Abaver et al.,19 reported $24 \%$ in Nasarrawa, Sanyaolu et al., ${ }^{20}$ reported 33.8\% in Lagos, Ibrahim et al.,21 reported $61.4 \%$ in Jos and Inabo et al.,22 reported 70.6\% in Zaria.

Young adults aged 21-30 years had the highest number of participants (154) and in turn the highest prevalence of parasitic infection (35.1\%). This depicts the high sexual activity and vulnerability, economic dependence and occupational exposure among this age group in the study area. This is in tandem with the report from NACA, that young Nigerian adults aged 15-24 accounted for most of the HIV prevalence in 2010.23 Female participants (32.5\%) were observed to be more infected than the males (24.1\%) but there was no significant difference in the presence of infection according to gender $(\mathrm{P}>0.05)$. This result is in tandem with that reported by Inabo et al., and Etok et al., who had $78.6 \% 10.3 \%$ infection rate in female participants respectively. ${ }^{14,22}$ Women have been reported to be the most vulnerable group and in Nigeria they were reported to have accounted for 170,431 new HIV infections in 2011.23 Cultural factors and education were said to be a contributing factor.

Protozoan infections have remained a threat to the health of HIV/AIDS patients. In this study, protozoan infection (21.0\%) was more prevalent than helminthes (8.0\%). This finding is similar to what was reported in Zaria by Inabo et al.,22 This study also correlate the prevalence of intestinal parasites of the participants with their CD4 counts. The prevalence of intestinal parasites of $15.0 \%$ was observed to be corresponding with low CD4 counts ( $<200), 12.5 \%$ was observed in the moderate CD4 counts (201-400) and 1.5\% in high CD4 counts (>400).

Protozoa was the most common parasite infection among subjects in the low CD4 counts group. Protozoan infection was observed to be $12.0 \%$ while $3.0 \%$ was for helminthes infection in the low immunity group. Opportunistic parasite infections were observed to be more common in the low immunity group (8.5\%) as compared with $1.5 \%$ in the moderate immunity group. This result shows that though the patients are placed on HAART, reduction in the CD4 count of $<200$ results in susceptibility to opportunistic infections, which took advantage of deficient cellmediated and humoral defense mechanisms as well as the limitation of HAART to curb secondary infections. Also, the absence of opportunistic intestinal infections in the high immunity group indicates that there was no breakdown in immunity to allow the establishment of these parasites.

Crytosporidium spp had a higher prevalence (27.6\%) in the low immunity group. This is lower than that reported by Adamu and Petros, and
Malaji et al., who reported $62.5 \%$ and $54 \%$ in Ethiopia and India respectively. 17,24

This study has shown that patients on HAART are vastly infected with intestinal parasite infection and the need to put in place, a process of routine screening and treatment for intestinal parasites among this category of patients for improved management of their ailment.

\section{References}

1. UNAIDS, WHO. AIDS epidemic update. 2007. Available from: http:/data.unaids.org/pub/EPISlides/2007/20 07_epiupdate_en.pdf

2. Adesiji Y0, Lawal R0, Taiwo SS, et al. Cryptosporidiosis in HIV infected patients with diarrhoea in Osun State, South Western Nigeria. Eur J Gen Med 2007;4: 119-22.

3. Bachur TP, Vale JM, Coêlho IC, et al. Enteric parasitic infections in HIV/AIDS patients before and after the highly active antiretroviral therapy. Braz J Infect Dis 2008;12:115-22.

4. Cimerman S, Cimerman B, Lewi DS. Prevalence of intestinal parasitic infections in patients with acquired immunodeficiency syndrome in Brazil. Int $\mathbf{J}$ Infect Dis 1999;3:203-6.

5. Cimerman S, Castañeda CG, Juliano WA, Palacios R. Perfil das enteroparasitoses diagnosticadas em pacientes com infecção pelo vírus HIV na era da terapia antiretroviral potente em um centro de referência em São Paulo, Brasil. Parasitol Latinoam 2002;57:111-9.

6. Ramakrishnan K, Shenbagarathai R, Uma A, et al. Prevalence of intestinal parasitic infestation in HIV/AIDS patients with diarrhea in Madurai City, South India. Jpn J Infect Dis 2007;60:209-10.

7. UNAIDS, WHO. Report on the global HIV/AIDS epidemic. 2002. Available from: http./data.unaids.org/pub/Report/2002/brglob al_aids_report_en_pdf_red_en.pdf

8. Botero JH, Castaño A, Montoya MN, et al. A preliminary study of the prevalence of intestinal parasites in immunocompromised patients with and without gastrointestinal manifestations. Rev Inst Med Trop São Paulo 2003;45:197-200.

9. Current WL, Gracia LS. Cryptosporidiosis. Clin Microbiol Rev 1991;4:325-58.

10. Kurniawan A, Karyadi T, Dwintasari SW, et al. Intestinal parasitic infections in HIV/AIDS patients presenting with diarrhoea in Jakarta, Indonesia. Trans R Soc Trop Med Hyg 2009;103:892-8.

11. National Population Commission. Nigeria Population and housing census 2006. Available from: http://catalog.ihsn.org/ index.php/catalog/3340

12. Offiong DA. An introduction to the Ibibio of
Nigeria. Clacton-on-Sea: Apex Books Ltd; 2008. pp 13-20.

13. Arora DR, Arora BB. Textbook of medical parasitology. 3rd ed. New Delhi: CBS Publisher; 2010. pp 156-170.

14. Etok NA, James E, Mboto CI, Sunde MU. Intestinal parasitic infections in HIV positive patients attending the General Hospital Calaber-Cross River State, Nigeria. Wrld J Appl Sci Tech 2010;2:76-86.

15. Missaye A, Dagnew M, Alemu A, Alemu A. Prevalence of intestinal parasites and associated risk factors among HIV/AIDS patients with pre-ART and on-ART attending Dessie hospital ART clinic, Northeast Ethiopia. AIDS Res Ther 2013;10;7.

16. Nkenfou CN, Nana CT, Payne VK. Intestinal parasitic infections in HIV infected and noninfected patients in a low HIV prevalence region, West-Cameroon. PLoS One 2013;8:e57914.

17. Adamu H, Petros B. Intestinal protozoan infections among HIV positive persons with and without antiretroviral treatment (ART) in selected ART centers in Adama, Afar and Dire-Dawa, Ethiopia. Ethiopia J Health Dev 2009;23:133-40.

18. Abaver DT, Nwobegahay JM, Goon DT, et al. Prevalence of intestinal parasitic infections among HIV/AIDS patients from two health institutions in Abuja, Nigeria. Afr J Health Sci 2011;11:S24-7.

19. Abaver DT, Nwobegahay JM, Goon DT, et al. Enteric parasitic infections in HIV-infected patients with low CD4 counts in Toto, Nigeria. Pakistan J Med Sci 2012;28:630-3.

20. Sanyaolu A0, Oyibo WA, Fagbenro-Beywru AF, et al. Comparative study of entero-parasite infections among HIV sero positive and sero-native patient in Lagos, Nigeria. Acta Tropica 2011;120:268-72.

21. Ibrahim AK, Ikeh EI, Malu A, et al. Intestinal parasitosis in human immunodeficiency virus (HIV) infected adults with chronic diarrhoea at Jos University Teaching Hospital, Nigeria. Internet J Parasit Dis 2007;2.

22. Inabo HI, Aminu M, Muktar H, Adeniran S. Intestinal parasitic infections associated with Diarrhoea in HIV/AIDS. World J Life Sci Med Res 2012;2:43-7.

23. National Agency for the Control of AIDS. Federal Republic of Nigeria: global AIDS response. Country progress report. 2012. Available from: http:/www.unaids.org /sites/default/files/en/dataanalysis/knowyourresponse/countryprogressreports/2012countries/Nigeria\%202012\%20GARPR\%20Report \%20Revised.pdf

24. Malaji SM, Bajaj G, Kora SA, et al. Study of opportunistic parasitic infections at various level of immune suppression in HIV/AIDS patients presenting with diarrhea. J Pharm Biomed Sci 2012;20:1-3. 